Georgia State University

ScholarWorks @ Georgia State University

$12-2017$

\title{
Preservice and Early Career Teachers' Preconceptions and Misconceptions about Making in Education
}

Jonathan Cohen

Georgia State University

W. Monty Jones

Virginia Commonwealth University

Shaunna Smith

Texas State University - San Marcos

Follow this and additional works at: https://scholarworks.gsu.edu/ltd_facpub

Part of the Instructional Media Design Commons

\section{Recommended Citation}

Preservice and Early Career Teachers' Preconceptions and Misconceptions About Making in Education Jonathan D. Cohen, W. Monty Jones \& Shaunna Smith Journal of Digital Learning in Teacher Education Vol. 34, Iss. 1, 2018. doi: https://doi.org/10.1080/21532974.2017.1387832

This Article is brought to you for free and open access by the Department of Learning Sciences at ScholarWorks @ Georgia State University. It has been accepted for inclusion in Learning Sciences Faculty Publications by an authorized administrator of ScholarWorks @ Georgia State University. For more information, please contact scholarworks@gsu.edu. 
Preservice and Early Career Teachers'

Preconceptions and Misconceptions about Making in Education 


\title{
Preservice and Early Career Teachers' Preconceptions and Misconceptions about Making in Education
}

\begin{abstract}
This qualitative study examined preservice and early career teachers' preconceptions and misconceptions about making in education. Eighty-two preservice and early career teachers participated in brief, one-time maker workshops, then wrote reflections on their experiences. Using constant comparative analysis, researchers uncovered two common misconceptions held by the participants. The first was that making in education consisted of hands-on activities designed to achieve specific content learning objectives. The second was that making was largely dependent on the use of advanced manufacturing tools, such as 3D printers. Such misconceptions could negatively impact the potential of making in education. Recommendations for resolving these misconceptions are presented, along with recommendations for future research.
\end{abstract}


Preservice and Early Career Teachers' Preconceptions and Misconceptions about Making in Education

The maker movement is a growing community of individuals who engage in making, which is often referred to as the construction, deconstruction, or remixing of physical or digital artifacts. It typically occurs within a community of makers, situated both in local spaces (e.g., makerspaces, libraries, afterschool programs, etc.) and in broader online communities within which makers share both the processes and products of their making. As a process, making tends to involve makers who work collaboratively (Agency by Design, 2015; Kuznetsov \& Paulos, 2010; Vossoughi \& Bevan, 2014) on interdisciplinary projects (Blikstein, 2013; Vossoughi \& Bevan, 2014), which require the practical application of knowledge and skills (Sheridan et al., 2014). There is also limited evidence which suggests that young makers tend to be a diverse group (Peppler, Maltese, Keune, Chang, \& Regalla, n.d.), and that making has the potential for further diversification, particularly in the science, technology, engineering, and mathematics (STEM) disciplines (Barton, Tan, \& Greenberg, in press; Buchholz, Shively, Peppler, \& Wohlwend, 2014).

Because many of these elements align with progressive perspectives on what effective formal K-12 education should look like, making has attracted the attention of educators and education researchers who are interested in leveraging maker principles in formal education. Correspondingly, teacher education programs are also beginning to consider how to prepare their graduates to facilitate the integration of making into their practice (Authors, 2017a).

Research has demonstrated that an important factor determining teachers' effective integration of technology into their practice is a belief system which values the role of technology in a successful learning environment (Ertmer, 2005; Ertmer \& Ottenbreit-Leftwich, 2010; Kim, Kim, Lee, Spector, \& DeMeester, 2013). Preservice and early career teachers enter 
their teacher preparation programs or early career development opportunities with conceptions developed prior to formal instruction regarding technology and education, called preconceptions (Hashweh, 1986; Posner, Strike, Hewson, \& Gertzog, 1982). These preconceptions can become misconceptions, defined here as conceptions which differ meaningfully from widely accepted scientific conceptions (Larkin, 2012). These misconceptions can in turn inform their beliefs regarding education. In part, the role of teacher preparation programs is to help preservice teachers move "beyond naïve beliefs, $[\ldots]$ to embrace more defensible views of teaching, learning, subject matter and students" (Feiman-Nemser, 2008, p. 698). A precursor to helping teachers move beyond these misconceptions is to understand the preconceptions on which they are based.

The purpose of this study is to understand preservice and early career teachers' preconceptions and misconceptions about making. To that end, it examined the written reflections submitted by 79 preservice teachers and 3 early career inservice teachers following their participation in an introduction-to-making workshop to answer the following research question: What misconceptions regarding making in education did these preservice and inservice teachers hold? This work is important in order to inform the development of frameworks and learning opportunities which can support preservice and early career teachers' abilities to leverage making and maker mindsets in their classrooms. Addressing preconceptions in this way can help to improve transfer between theory and practice in preservice teachers (Wubbels, 1992), leading to the use of making as an agent of pedagogical change as opposed to a simple add-on to traditional instruction. 


\section{Literature Review}

\section{Constructionism}

Scholars tend to point to Papert's constructionism (Papert, 1980, 1991) as the theoretical foundation of the modern maker movement (Halverson \& Sheridan, 2014; Martinez \& Stager, 2013; Vossoughi \& Bevan, 2014). Constructionism "views learning as building relationships between old and new knowledge, in interactions with others, while creating artifacts of social relevance" (Kafai, 2006, p. 35). In this way, it is commonly situated as an offshoot of Piagetian constructivism (Ackermann, 2001; Oliver, 2016; Vossoughi \& Bevan, 2014), which holds "that the construction of knowledge happens remarkably well when students build, make, and publicly share objects" (Blikstein, 2013, p. 5). Construction of knowledge, though, is not the ultimate end goal of constructionist learning environments. Rather, constructionism views a longer-term change in learners' stance towards learning itself as its end goal. As Papert wrote in Mindstorms (1980), constructionism "means supporting children as they build their own intellectual structures with material drawn from the surrounding culture" (p. 31-2). This occurs as children participate iteratively in a "cycle of self-directed learning... by which learners invent for themselves the tools and mediations that best support the exploration of what they most care about" (Ackermann, 2001, p. 4). The process of developing these "intellectual structures" via self-generated tools, both physical and otherwise, leads ideally to the increased capacity and desire of learners to construct knowledge (Kafai, 2006).

\section{Tools}

The maker movement tends to be closely associated with modern digital technologies. Just as Papert's children's programming language, Logo, and the "turtles" they controlled characterized early constructionist education (Papert, 1980), so do 3D printers, laser cutters, 
microcontrollers, and block-based visual coding languages like Scratch (Resnick et al., 2009) characterize the modern maker movement. Beyond their utility in the construction and automation of artifacts, modern maker technologies have been described as "emancipatory" (Blikstein, 2013, p. 5), drastically lowering the barriers of entry into the world of production and automation through continued improvement in the technologies' entry costs, ease of use, and an open-source ethos (Anderson, 2012; Dougherty, 2012; Hatch, 2014; Martinez \& Stager, 2013).

Just as modern digital fabrication and automation technologies have facilitated growth in the act of making, modern communication technologies have also enabled the growth in maker communities. Digital communities of interest (Collins \& Halverson, 2009), untethered by geographic location, have given makers near-instantaneous access to the collective knowledge and wisdom of the broader maker community. It is important to note, however, that while modern digital technologies have provided much of the impetus for the growth of the maker movement and supplied it with much of its character, they are not essential to the process of making. Making can and does occur using traditional analog tools and technologies, yet it is the advanced manufacturing tools, such as $3 \mathrm{D}$ printers and microcontrollers, which often function as metonymies for making as a whole.

\section{Conceptual Change, Technology, and Teacher Education}

Long used as a foundation for researching the development of knowledge in science education, the theory of conceptual change states that learners often approach new ideas or concepts with preconceptions, which seem plausible but often do not align with more widely held expert understandings of those ideas or concepts (Posner et al., 1982). These preconceptions can ossify into misconceptions, and, according to Posner et al. (1982), changing these misconceptions 
can be strenuous and potentially threatening, particularly when the individual is firmly committed to prior assumptions. We have seen that people resist making such changes, unless they are dissatisfied with their current concepts and find an intelligible and plausible alternative that appears fruitful for further inquiry. (p. 223)

Therefore, understanding preconceptions is a necessary first step for effecting conceptual change.

Like other learners, preservice teachers enter teacher training programs with a set of preconceptions and misconceptions about teaching. Compared with research on student misconceptions, relatively little research has been conducted on preconceptions and misconceptions in preservice teachers (Compton, Davis, \& Correia, 2010), though there are a few studies which examine teaching and technology integration (Katić, 2008; Niederhauser, Salem, \& Fields, 1999; Sadera, 2001; Sadera \& Hargrave, 2005). Recently, Compton, Davis, and Correia (2010) used a conceptual change framework to analyze preservice teachers' preconceptions and misconceptions of virtual schooling. Analyzing journal writings from 65 preservice teachers enrolled in a virtual seminar on virtual schooling, they found that students held a number of preconceptions and misconceptions about virtual schooling, and that curricular interventions designed to address these pre/misconceptions could be effective.

\section{Methods}

\section{Context}

The research question guiding this study was, what misconceptions regarding making in education did these preservice and inservice teachers hold? To explore this question, researchers employed a qualitative exploratory design. An exploratory design enables the researchers to gain insights and establish hypotheses (Creswell, 2013) because there is little 
research in this area. This study was conducted at three large research universities located in the United States during Spring 2016. Each of the three universities are located in a different geographic region (i.e., Southeast, mid-Atlantic, and Southwest), though they are similar in that they are traditional teacher preparation programs, and their graduates tend to work in schools which primarily serve underrepresented populations.

A total of 82 university students participated in the research, 79 of whom were preservice teachers. The other 3 participants were early career inservice teachers. The participants each attended one of seven 2.5-hour maker workshops which introduced them to maker technologies and the pedagogies they support. The workshops consisted of brief lectures which introduced the concept of making, discussions of the relationships between making and common pedagogies, demonstrations of both non-digital and digital maker tools (e.g. design software, 2D CNC vinyl cutting machine, 3D modeling software and 3D printing, computer programming, and interactive electronic microcontrollers), hands-on design activities, and small group discussions. Workshop leaders intentionally included examples of how making could be integrated into both elementary and secondary classrooms in order to be inclusive of the various contexts the participants would eventually work. Two primary objectives of the workshops were to help participants to develop understandings of the nature of a maker mindset and of the affordances of various maker tools. The ultimate goal of the workshops was to help the participants to learn that it is the processes associated with making (e.g., collaboration, iteration, problem solving, etc.) which hold the potential to most positively impact student learning, more so than the use of any specific digital technologies.

\section{Data Collection}


Between a week and a month after the workshops, participants completed online reflective journal entries, which were submitted to the research team. The reflective journal prompt was as follows:

1. Create a summary of your experience in this workshop, including processes you engaged in, artifacts you created, and implications for your future practice. Specifically address the following topics:

a. Describe what you have discovered about yourself as an individual during this workshop.

b. Describe what you have discovered about yourself as an educator during this workshop.

c. Discuss the educational implications (i.e. interdisciplinary content connections) and practical concerns of integrating maker activities and tools (i.e. design software, 2D paper cutting machines, 3D printers, simple electronics) into student learning experiences (i.e. compare and contrast implications for informal afterschool or workshop settings with formal/traditional classroom settings; ways of overcoming potential hurdles).

d. Describe how will you apply what you've learned during this workshop into your future practice.

All reflective journal entry files were formatted for use in Nvivo qualitative analysis software and pseudonyms were assigned to all participants in order to ensure privacy.

\section{Data Analysis}

Constant comparative analysis technique (Glaser \& Strauss, 1967; Strauss \& Corbin, 1990) was used to uncover participants' preconceptions and misconceptions about 
making. The reflective journal entries were imported into Nvivo software and analyzed by two authors. In order to address inter-rater reliability (Maxwell, 2013), the first round of analysis included preliminary open coding of a subset of data, which involved the researchers coding separately to dissect and categorize the data. The researchers then met to discuss the discrepancies and negotiated modifications in the coding procedures. The resulting preliminary open coding resulted in $\mathbf{2 8}$ codes, such as: a) barriers to implementation, b) questioning school support, c) benefits to teaching science, d) failurepositivity, and e) confidence. Secondary analysis with axial coding was conducted by both researchers, which involved disaggregating core themes and resulted in five themes, including a) focus on activities for content learning, b) focus on tools, c) maker activities are too hard, d) maker activities require too much time, and e) need for expensive equipment or advanced technology skills. A third round of analysis used selective coding to select a core category and validate relationships between the other themes, resulting in two major themes: a) making as activities, and b) focus on tools. Finally, all three researchers met and analyzed the themes that emerged from the coding. This multiphase process with multiple researchers coding was used to establish trustworthiness. Constant comparative analysis techniques were used in this study; however, the development of grounded theory was not within the scope of what is reported in this article because the initial sampling did not seek disproving evidence or participants. Future work will explore grounded theory development.

\section{Findings}

Analysis of the five axial codes revealed two primary themes. The first theme was derived from the first conceptual code (focus on activities for content learning), and suggests that participants largely viewed making as a set of activities that could address various content areas, 
but rarely considered how making may promote broader skill development or mindset changes. The second theme emerged through aggregation of the four remaining codes, and suggests that participants focused primarily on the tools and technologies used in making activities, and envisioned multiple barriers of use due to the perceived need for expensive equipment and advanced technological skills.

\section{Making as Activities}

Most participants in this study envisioned making in their future classrooms as a set of activities that could address specific content standards. For instance, one participant expressed this view of making as classroom activity by suggesting it could "be used in a classroom with young children to teach force and motion and other physical science concepts." Another suggested that a 3D printer could be employed in the content area of English language arts by assisting students in "creating their own characters or just creating their own writing prompt." Math and science content areas were mentioned often, with participants noting that "the 3D printer would be awesome to have to test multiple scientific topics," and that a 2D digital die cutter could be utilized to help students "learn about shapes in geometry." In addition, participants suggested that maker activities could promote interdisciplinary connections between content areas. In reflecting on their experiences in the workshop, one participant noted that “there's tons of science, math, art, or history projects that could derive from pretty much everything we used in the workshop," and another stated "the interconnection of interdisciplinary content is what made these activities in the workshop so engaging." Despite stray mentions of non-STEM disciplines and interdisciplinary connections, participants largely envisioned the use of these activities in the math and science content areas. As one participant noted while reflecting on the workshop, "this [workshop] was especially helpful in adding math to the science 
curriculum. We dealt with a lot of geometry and scaling while doing the 3D printing." In nearly all cases in which workshop participants speculated on the role of making in education, they focused on applications specifically tied to content knowledge development.

This lens of making as a set of activities to address specific content areas sometimes caused participants to struggle to find connections between making activities and specific content areas. One participant noted, "As an educator, though, I found myself slightly frustrated that I could not easily figure out legitimate teaching applications for my own [future] English class.” Another participant expressed a similar sentiment in terms of state mandated standardized testing, and noted, "since standardized testing is such a concern for many teachers, I can see where people would be hesitant to use makerspace on a daily basis." Through these quotes, the limiting nature of seeing making through this particular lens becomes apparent.

Such thinking about making as a series of often STEM-based activities designed to support specific content knowledge development demonstrates these preservice teachers' misconceptions about the potential roles of making across the curriculum, in that they do not take into account the theoretical foundations of making as well as the emerging body of evidence of the benefits of making in educational environments. In thinking of making in such narrow terms, the participants were not really talking about making at all, but rather, the types of traditional hands-on activities that have existed for decades in K-12 classrooms. For example, one participant envisioned an activity in which "as a teacher, I could do a unit on using the 3-D printer, connecting it to what the inside of a plant looks like and having the students have their own plant cells as a study tool." This kind of traditional hands-on activities stand in contrast to a more open-ended, iterative making experience, in which creativity, collaboration, and a degree of student agency over the process play an essential role. 
While hands-on activities can achieve certain narrow, content-specific learning objectives, they do not necessarily lead students to access and develop certain other dispositions, skills, and mindsets that can be fostered by making. In their summary of existing literature on making in education, Vossoughi and Bevan (2014) identified three major areas in which research has shown making's ability to impact learning. The first area involved facilitation of students' active participation in learning, which was further divided into three areas: supporting new “intellectual dispositions" (p. 14); connecting learning to familiar practices, thereby honoring students' individual and diverse practices and ways-of-knowing; and advancing student agency. The second area included expanded curricular design opportunities, such as contextualizing learning, facilitating interdisciplinary learning, and "encouraging intellectual risk-taking, experimentation and iteration" (p. 23). The third and final area involved the benefits derived from the types of collaborative communities that characterize making environments, including helping students to learn to work together in "authentic intellectual activity" (p. 28), embrace “intellectual diversity” (p. 28), and develop leadership skills. Step-by-step assembly or cookbook recipe-style activities are less likely to engender these types of benefits.

While the participants in this study largely considered making as a set of activities to address content-area learning outcomes, some did recognize broader educational benefits of these types of activities. One participant summed up their perspective on this in terms of the benefits for their future students:

These tools can get students thinking in different ways, ways they may not commonly think in a classroom. Having experiences with these tools at a young age could give students the mindset of innovation, holistic thinking, mechanical 
knowledge, and hands-on experiences that they could carry with them throughout the rest of their lives.

Those who did mention benefits beyond content-level learning focused primarily on the inherent failure-positive mindset embodied within maker activities. In considering this in their future classroom, one participant noted:

I need to be prepared to promote failure as a positive and to support students through a trial and error process. Knowing how frustrated I can become with new technology, I can emphasize with students who feel similar frustrations and help them solve problems without feeling like there first attempts were not valid just because they did not work.

Another participant articulated a similar thought by reflecting:

I'm going to have to be ok with them not having much of a product to show at the end of every unit because they're going to learn more from trying and failing than from me leading them around by the nose. I'm going to have to set up structures in which trying and failing do not destroy students' grades and subsequently their confidence.

In these quotes, participants demonstrated a recognition of the value of failure-positive maker activities and began to conceptualize how they could operationalize activities in their future classrooms to support growth in this area. However, this perspective on the role of making in classrooms was uncommon, in comparison to the general viewpoint of making as a way to achieve narrowly cast learning objectives. 


\section{Focus on Tools}

In relating the emergence of maker tools in K-12 contexts to the rise of computers in $\mathrm{K}$ 12 classrooms, Martin (2015) stated:
Although thoughtful researchers of and advocates for bringing making into education, such as those cited throughout this article, uniformly argue for a multifaceted understanding of making, the history of the adoption of computers in schools suggests a lurking danger: a seductive, but fatally flawed conceptualization of the Maker Movement that assumes its power lies primarily in its revolutionary tool set, and that these tools hold the power to catalyze transformations in education. (p. 37)

This misconception was evident in the reflections of the participants as they prominently focused on the tools, and the necessary technological skills to use the tools, as they considered making in their future classrooms. In considering making through a tool-centric lens, participants limited their conceptualizations of making activities and perceived multiple barriers to implementation, including age appropriateness, time required for implementation, low self-efficacy for facilitating making activities, and cost and access issues in their future classrooms.

Participants' conceptualizations of making in their future classrooms were often limited by their focus on maker tools and technologies. For example, recall that one preservice English language arts teacher suggested that a 3D printer could be used to help students in developing characters or writing prompts. It is clear that this participant viewed making through the lens of a 3D printer, a tool closely associated with making in the popular consciousness, and as a result, developed a conception of making which would be unlikely to result in the types of learning afforded by making. Moreover, such an application of technology (i.e., 3D computer-aided 
design software and 3D printing) to facilitate activities (i.e., developing writing prompts or actualizing characters) which can be accomplished with less overhead and expenditure of resources and energy holds the potential to distract from the learning objectives and to strain unnecessarily limited classroom resources.

In many cases, this focus on tools and technologies resulted in participants' focus shifting from the potential benefits of making in the classroom to the various barriers to its implementation. Often these concerns revolved around the ability of their future students to use certain tools and technologies. Participants' concerns included such items as, "I felt like these programs would be far too advanced for younger grades, so I would probably limit the use to 4th grade and up," "these materials were more age appropriate for upper elementary", and "I think that younger students may not be able to work some of the technology, and may get frustrated while trying." As evidenced through these quotations, many participants conceptualized making activities solely through the use of a small number of technologies and tools, ones they deemed too advanced for younger students. This view stands in contrast to research that suggests that making can be effective in achieving a variety of learning objectives with younger students (Authors, 2013; Chu, Quek, Bhangaonkar, Ging, \& Sridharamurthy, 2015).

This misconception that making was focused on the use of advanced manufacturing technologies like 3D printers and microcontrollers led to some participants conceptualizing making activities as requiring an onerous amount of instructional time. In considering the role of 3D printing, one participant noted, "I never knew how much I needed instant gratification until I was staring at the 3-D printer taking forever." Another articulated a similar concern, stating, "I think technologies like the 3D printer [are] better suited for after school activities because of the time commitment required to implement it." These statements demonstrate the primary focus of 
these participants on the tools, as opposed to the making activities. When considering the Scratch block-based programming language, another participant stated, "it takes a lot of time to make something in Scratch! Equally true with 3D modeling. If I'm going to have a makerspace in my classroom, it's going to have to be an after school kind of program." This perception was popular among the participants as many felt that the time requirement to utilize the tools was better suited for after-school activities. This was evidenced by several participants who reported, "These tools may work better in after-school programs and workshops, so students can begin to learn to use them without taking too much time from instructional time," and "I could incorporate this technology through after-school workshops, that way my students could do more complex activities." It may indeed be the case that making activities which leverage these types of tools would take longer than equivalent activities which used more traditional, analog tools. However, the misconception that these tools are somehow necessary to or synonymous with making could lead to a situation in which educators summarily dismiss the infusion of making into their practice.

By focusing primarily on the tools sometimes used in making activities, teachers also frequently expressed a lack of confidence in their own abilities to use the tools as well as their perceived limited access to these tools. Most participants in this study had little-to-no previous experience with these types of activities and tools, and by utilizing a tool-centric view of making in their future classrooms, they perceived a lack of technical expertise as a barrier to implementation. One participant humorously noted, "what I discovered about myself is how 'old' I am. I felt like my mom trying to navigate through Facebook." Others reported similar perceptions by stating "having technology shortcomings will hinder your ability to work on the computer to create the 3D figure," "I am not very strong when it comes to engineering," "I need 
to have a better understanding of the technology before I try to teach students how to use it," and "for me to personally teach how to use the equipment and computer programs, I feel like I would need a completely new degree." In the last quote in particular, the participant's conceptualization of making in terms of teaching how to use the equipment - as opposed to how making activities can support student learning_-is apparent.

Finally, in considering the tools as the main catalysts for making activities, participants perceived limited access to more advanced tools and technologies that would be required to implement making activities in their future classrooms. Participants largely viewed maker tools and technologies as expensive and inaccessible. Several participants conveyed this sentiment by statements, such as, "These machines are expensive and working with the upkeep of them adds up," "Some practical concerns about the Maker tools is simply having the resources," and "The tools we used, like the 3-D printer is expensive and would not be readily accessible for everyday classroom use." Several participants, reflecting on their student-teaching experience, noted that funding in their schools was an ongoing issue, and one participant noted that "these are very expensive and would require more funds than [her school division] currently has."

As evidenced through these participants' quotes, the misconceived focus on the tools sometimes used in making activities limited many of their abilities to envision making activities in their future classrooms. This may be, in part, due to the nature of the workshops they attended, in which they were exposed to several emerging technologies and tools, such as 3D printers and digital die cutters. Though modern maker technologies have become simpler to use in the past years (Hsu, Baldwin, \& Ching, 2017), many of them still require a certain amount of prior knowledge to implement, and barriers exist for their use, particularly among younger students. Similarly, the cost of purchasing and operating this equipment has either declined or been 
eliminated in some cases, but in many circumstances accessing maker technologies remains unfeasible. Many participants (quite correctly) acknowledged these issues, but they interpreted them as barriers for integrating making as a whole into their future classrooms.

\section{Discussion and Implications}

Analysis of workshop participants' journal responses to an introductory workshop on making indicated the presence of two major misconceptions regarding making: making is a series of activities that teachers can use to achieve only narrow, content-based learning objectives, and that certain tools are central to the practice of making. Each of those misconceptions has the potential to impact negatively the preservice teachers' integration of making into their future practices. The conception of making as a narrowly focused activity limits the potential benefits of making in the classroom. If preservice teachers do not believe that a behavior, such as making, would positively impact students, they are less likely to integrate that behavior into their practice (Authors, 2017b). Viewing making activities through a narrow, content-focused lens can result in teachers deciding that making is not worth the added expense of time and energy, especially when compared to more traditional pedagogies. Similarly, if preservice or early career teachers' conceptions of making are focused on the presence of advanced manufacturing tools, such as 3D printers, digital die cutters, laser cutters, and microcontrollers, then they may be dissuaded from integrating making into their practice, due to the overhead associated with the use of such tools (i.e., cost, complexity, time) and their own lack of self-efficacy related to the tools (Authors, 2017b; Mueller, Wood, Willoughby, Ross, \& Specht, 2008). The lack of obvious applicability of those advanced manufacturing tools to nonSTEM domains could also stunt the exploration of making in those domains. 
In order to effectively prepare preservice teachers to integrate making into classroom settings, the findings of this study suggest that teacher preparation programs should address preconceptions and misconceptions regarding making as part of any maker education component they offer. The misconception regarding making as solely a narrowly focused activity could be addressed by having the preservice or early career teachers participate as students in a making experience, supplemented by activities such as guided reflection to help them to understand the broader benefits of making (Sator \& Bullock, 2017). Clapp et al. (2017) suggest two broad primary benefits of maker-centered learning: developing student agency and building character. They describe developing student agency by allowing students opportunities to make things that are meaningful to them as well as their communities and taking ownership over the process. Building character is described as building confidence in one's abilities as a maker, as well as developing positive thinking dispositions such as risk taking, persistence, and learning from failure. Ensuring these types of broader benefits are explicit in learning experiences for preservice and early career teachers, as well as having them reflect on these types of benefits as they engage in authentic maker-centered learning activities may help address their misconceptions of the limited benefits of making. In addition, teacher educators can develop and implement maker-centered learning activities that specifically consider these benefits, thereby modeling the instructional design and implementation of these activities and helping to bridge theory with practice.

The misconceptions that arise from an overemphasis on advanced manufacturing technologies in making could be addressed through two complementary approaches. First, curriculum designers can create making opportunities which are not organized around tools, but rather on a particular design challenge or objective. By removing focus from them, the tools 
ideally would become transparent, allowing for the student-makers to employ whichever tools are appropriate for the task. Correspondingly, teacher educators can frame maker education in terms of the technological, pedagogical, and content knowledge framework (TPACK; Mishra \& Koehler, 2006), which holds that proper technology integration considers the application of technology in combination with pedagogy and content, and recognizes the context in which the technology integration is to occur. Use of this framework may assist preservice and early career teachers in conceptualizing effective maker-centered learning experiences with and without advanced manufacturing technologies through consideration of the pedagogies maker-centered learning experiences support, and the alignment of maker activities with various content areas. In addition, linking making to existing learning theories (e.g., constructionism and critical pedagogies) and learning strategies (e.g., experiential learning, problem-based learning) could serve to deemphasize the role of specific tools and technologies, thereby allowing teacher candidates to focus on pedagogical strategies supported through maker learning activities.

\section{Conclusion}

This study helps to uncover misconceptions that preservice and early career teachers have about making. Armed with this knowledge, teacher educators and teacher preparation programs can target these preconceptions and misconceptions in order to increase the chances that their maker education efforts would result in more successful outcomes. This study does have various limitations, however, which encourage caution in interpreting its findings. As this was the first study examining preservice and early career teachers' preconceptions and misconceptions with regard to making, the researchers were not able to compare results with other work. Also, though the participants were drawn from three universities located in different parts of the country, each 
program tends to place teachers into school systems with primarily underserved student populations. A participant pool working in a more varied educational context could impact the findings. Additionally, due to the nature of the workshops, researchers were not able to conduct follow up conversations regarding preconceptions and misconceptions with the participants. The addition of such data could provide more nuance to this type of study. Finally, as mentioned above, the design of the workshops involved the use of advanced manufacturing technologies, which could have contributed to some of the participants' focus on those technologies in their journal responses. These limitations notwithstanding, this research advances teacher educators' understanding of preservice and early-career teachers' preconceptions and misconceptions, and informs the design of future maker education efforts.

Along with the recommendations for practice above, the researchers also recommend that future research could examine the preconceptions and misconceptions of preservice and early career teachers in different contexts. The present study occurred in conjunction with maker workshops, which likely impacted the foci of the participants. Future research could examine preservice and early career teachers' preconceptions and misconceptions independent of maker workshops, curricular units, or courses. Finally, research could examine the impact of the recommendations for practice mentioned above on preservice and early career teachers' misconceptions.

\section{References}

Ackermann, E. (2001). Piaget's Constructivism, Papert's Constructionism: What's the difference? (pp. 1-11). Research Center in Education. https://doi.org/10.1.1.132.4253

Agency by Design. (2015). Maker-Centered Learning and the Development of Self: Preliminary findings of the Agency by Design project. Project Zero, Harvard Graduate School of Education. Anderson, C. (2012). Makers: The new industrial revolution. New York, NY: Crown. 
Authors, 2013.

Authors, 2017a.

Authors, 2017b.

Barton, A. C., Tan, E., \& Greenberg, D. (in press). The makerspace movement: Sites of possibilities for equitable opportunities to engage underrepresented youth in STEM. Teachers College Record, 119(7).

Blikstein, P. (2013). Digital fabrication and "making" in education: The democratization of invention. In J. Walter-Hermann \& C. Büching (Eds.), FabLabs: Of machines, makers and inventors (pp. 203222). Bielefeld: Transcript.

Buchholz, B., Shively, K., Peppler, K., \& Wohlwend, K. (2014). Hands on, hands off: Gendered access in crafting and electronics practices. Mind, Culture, and Activity, 21(4), 278-297.

https://doi.org/10.1080/10749039.2014.939762

Chu, S. L., Quek, F., Bhangaonkar, S., Ging, A. B., \& Sridharamurthy, K. (2015). Making the Maker: A Means-to-an-Ends approach to nurturing the Maker mindset in elementary-aged children. International Journal of Child-Computer Interaction, 5, 11-19.

https://doi.org/10.1016/j.ijcci.2015.08.002

Collins, A., \& Halverson, R. (2009). The Technology Enthusiasts’ Argument. In A. Collins \& R. Halverson (Eds.), Rethinking education in the age of technology: The digital revolution and schooling in America (pp. 9-29). New York, NY: Teachers College Press.

Compton, L., Davis, N., \& Correia, A. (2010). Pre-service teachers' preconceptions, misconceptions, and concerns about virtual schooling. Distance Education, 31(1), 37-54.

https://doi.org/10.1080/01587911003725006

Creswell, J. W. (2013). Research Design: Qualitative, Quantitative, and Mixed Methods Approaches. Los Angeles, CA: SAGE Publications.

Dougherty, D. (2012). The Maker Movement. Innovations: Technology, Governance, Globalization, 7(3), 11-14. https://doi.org/10.1162/INOV_a_00135 
Ertmer, P. A. (2005). Teacher Pedagogical Beliefs: The Final Frontier in Our Quest for Technology Integration? Educational Technology Research and Development, 53(4), 25-39.

Ertmer, P. A., \& Ottenbreit-Leftwich, A. T. (2010). Teacher technology change: How knowledge, confidence, beliefs, and culture intersect. Journal of Research on Technology in Education, 42(3), 255-284. Retrieved from http://www.tandfonline.com/doi/abs/10.1080/15391523.2010.10782551

Feiman-Nemser, S. (2008). Teacher learning: How do teachers learn to teach? In M. Cochran-Smith, S. Feiman-Nemser, D. John McIntyre, \& K. E. Demers (Eds.), Handbook of Research on Teacher Education: Enduring Questions in Changing Contexts (pp. 697-705). New York, NY: Routledge.

Glaser, B., \& Strauss, A. (1967). The discovery of grounded theory: Strategies for qualitative research. Chicago, IL: Aldine.

Halverson, E. R., \& Sheridan, K. (2014). The Maker Movement in Education. Harvard Educational Review, 84(4), 495-504. https://doi.org/10.17763/haer.84.4.34j1g68140382063

Hashweh, M. Z. (1986). Toward an explanation of conceptual change. European Journal of Science Education, 8(3), 229-249. https://doi.org/10.1080/0140528860080301

Hatch, M. (2014). The maker movement manifesto. New York, NY: McGraw-Hill Education.

Hsu, Y.-C., Baldwin, S., \& Ching, Y.-H. (2017). Learning through Making and Maker Education. TechTrends. Advance online publication. https://doi.org/10.1007/s11528-017-0172-6

Kafai, Y. B. (2006). Constructionism. In K. Sawyer (Ed.), The Cambridge Handbook of the Learning Sciences (pp. 35-46). Cambridge University Press. https://doi.org/10.1017/cbo9780511816833.004 Kalil, T. (2013). Have fun—learn something, do something, make something. In M. Honey \& D. Kanter (Eds.), Design, make, play: Growing the next generation of STEM innovators (pp. 12-16). New York, NY: Routledge.

Katić, E. K. (2008). Preservice teachers' conceptions about computers: An ongoing search for transformative appropriations of modern technologies. Teachers and Teaching: Theory and Practice, 14(2), 157-179. Retrieved from http://www.tandfonline.com/doi/abs/10.1080/13540600801983344

Kim, C., Kim, M. K., Lee, C., Spector, J. M., \& DeMeester, K. (2013). Teacher beliefs and technology 
integration. Teaching and Teacher Education, 29, 76-85. https://doi.org/10.1016/j.tate.2012.08.005

Kuznetsov, S., \& Paulos, E. (2010). Rise of the expert amateur: DIY projects, communities, and cultures. In Proceedings of the 6th Nordic Conference on Human-Computer Interaction: Extending Boundaries (pp. 295-304). Reykjavik, Iceland. https://doi.org/10.1145/1868914.1868950

Larkin, D. (2012). Misconceptions about “misconceptions”: Preservice secondary science teachers' views on the value and role of student ideas. Science Education, 96(5), 927-959. https://doi.org/10.1002/sce.21022

Martinez, S., \& Stager, G. (2013). Invent to learn: Making, tinkering, and engineering in the classroom. Torrance, CA: Constructing Modern Knowledge Press.

Martin, L. (2015). The promise of the Maker Movement for education. Journal of Pre-College Engineering Education Research, 5(1), 30-39.

Maxwell, J. A. (2013). Qualitative research design: An interactive approach (3rd ed.). Thousand Oaks, CA: Sage.

Mishra, P., \& Koehler, M. J. (2006). Technological pedagogical content knowledge: A framework for teacher knowledge. Teachers College Record, 108(6), 1017. Retrieved from http://onlinelearningcurriculumcommittee.pbworks.com/f/mishra.pdf

Mueller, J., Wood, E., Willoughby, T., Ross, C., \& Specht, J. (2008). Identifying discriminating variables between teachers who fully integrate computers and teachers with limited integration. Computers \& Education, 51(4), 1523-1537. https://doi.org/10.1016/j.compedu.2008.02.003

Niederhauser, D. S., Salem, D. J., \& Fields, M. (1999). Exploring teaching, learning, and instructional reform in an introductory technology course. Journal of Technology and Teacher Education, 7(2), $153-172$.

Oliver, K. M. (2016). Professional development considerations for makerspace leaders, part one: Addressing “what?” and “why?” TechTrends, 60(2), 160-166. https://doi.org/10.1007/s11528-016$0028-5$

Papert, S. (1980). Mindstorms. New York, NY: Basic Books. 
Papert, S. (1991). Situating constructionism. In S. Papert \& I. Harel (Eds.), Constructionism (pp. 1-11). Norwood, NJ: Ablex.

Peppler, K., Maltese, A., Keune, A., Chang, S., \& Regalla, L. (n.d.). The Maker Ed Open Portfolio Project: Survey of Makerspaces, Part I. Maker Education Initiative.

Posner, G. J., Strike, K. A., Hewson, P. W., \& Gertzog, W. A. (1982). Accommodation of a scientific conception: Toward a theory of conceptual change. Science Education, 66(2), 211-227. https://doi.org/10.1002/sce.3730660207

Resnick, M., Maloney, J., Monroy-Hernández, A., Rusk, N., Eastmond, E., Brennan, K., ... Kafai, Y. (2009). Scratch: Programming for All. Communications of the ACM, 52(11), 60-67. https://doi.org/10.1145/1592761.1592779

Sadera, W. A. (2001). Conceptual change-based instruction and preservice teacher technology preparation: a collective case study. Unpublished doctoral dissertation, Iowa State University. Retrieved from http://lib.dr.iastate.edu/rtd/453/

Sadera, W., \& Hargrave, C. (2005). Conceptual change in pre-service teacher technology preparation. In C. Vrasidas \& G. Glass (Eds.), Preparing teachers to teach with technology (pp. 291-302). Greenwich, CT: Information Age.

Sator, A. J., \& Bullock, S. M. (2017). "Making" as a catalyst for reflective practice. Reflective Practice, 18(2), 244-255. Retrieved from http://www.tandfonline.com/doi/abs/10.1080/14623943.2016.1268118

Sheridan, K., Halverson, E., Litts, B. K., Brahms, L., Jacobs-Priebe, L., \& Owens, T. (2014). Learning in the making: Comparative case study of three makerspaces. Harvard Educational Review, 84(4), 505-532. https://doi.org/10.17763/haer.84.4.brr34733723j648u

Strauss, A. L., \& Corbin, J. M. (1990). Basics of qualitative research: grounded theory procedures and techniques. Thousand Oaks, CA: Sage Publications.

Vossoughi, S., \& Bevan, B. (2014). Making and tinkering: A review of the literature. Committee on Successful Out-of-School STEM Learning. Retrieved from 
http://sites.nationalacademies.org/cs/groups/dbassesite/documents/webpage/dbasse_089888.pdf Wubbels, T. (1992). Taking account of student teachers' preconceptions. Teaching and Teacher Education, 8(2), 137-149. https://doi.org/10.1016/0742-051X(92)90004-M 